\title{
The anaphylatoxin C3a downregulates the Th2 response to epicutaneously introduced antigen
}

\author{
Seiji Kawamoto,, ${ }^{1,2}$ Ali Yalcindag, ${ }^{1}$ Dhafer Laouini, ${ }^{1}$ Scott Brodeur, ${ }^{1}$ Paul Bryce, ${ }^{1}$ Bao Lu, ${ }^{3}$ \\ Alison A. Humbles, ${ }^{3}$ Hans Oettgen, ${ }^{1}$ Craig Gerard, ${ }^{3}$ and Raif S. Geha ${ }^{1}$ \\ 'Division of Immunology, Children's Hospital and the Department of Pediatrics, Harvard Medical School, Boston, Massachusetts, USA. \\ ${ }^{2}$ Graduate School of Advanced Sciences of Matter, Hiroshima University, Higashi-Hiroshima, Japan. ${ }^{3}$ Division of Pulmonary Medicine and \\ Ina Sue Perlmutter Laboratory, Children's Hospital and the Department of Pediatrics, Harvard Medical School, Boston, Massachusetts, USA.
}

\begin{abstract}
Mechanical injury to the skin results in activation of the complement component $\mathrm{C} 3$ and release of the anaphylatoxin $\mathrm{C} 3 \mathrm{a}$. C3a binds to a seven-transmembrane $\mathrm{G}$ protein-coupled receptor, $\mathrm{C} 3 \mathrm{aR}$. We used C3aR ${ }^{-/-}$ mice to examine the role of $\mathrm{C} 3 \mathrm{a}$ in a mouse model of allergic inflammation induced by epicutaneous sensitization with OVA. $\mathrm{C}^{2} \mathrm{aR}^{-/-}$mice exhibited an exaggerated $\mathrm{Th} 2$ response to epicutaneous but not to intraperitoneal sensitization with OVA, as evidenced by significantly elevated levels of serum OVA-specific IgG1 and significantly increased secretion of the Th2 cytokines IL-4, IL-5, and IL-10 by antigen-stimulated splenocytes. Presentation of OVA peptide by $\mathrm{C}_{3} \mathrm{aR}^{-/-}$APCs caused significantly more IL-4 and IL-5 secretion by T cells from OVA-T cell receptor (OVA-TCR) transgenic mice compared with presentation by WT APCs. C3a inhibited the ability of splenocytes, but not of highly purified T cells, to secrete Th2 cytokines in response to TCR ligation. This inhibition was mediated by IL-12 secreted by APCs in response to C3a. These results suggest that C3aC3aR interactions inhibit the ability of APCs to drive Th2 cell differentiation in response to epicutaneously introduced antigen and may have important implications for allergic skin diseases.
\end{abstract}

\section{Introduction}

The complement cascade is an important system that consists of proenzymes that become activated sequentially to perform diverse biologic functions (1). The third component of the complement system, C3, is the pivotal molecule in this cascade, and its activation leads to the release of several peptides from the parent molecule. In a first step, C3 is cleaved to C $3 \mathrm{a}$ and C3b. Subsequently, $\mathrm{C} 3 \mathrm{~b}$ is cleaved to $\mathrm{iC} 3 \mathrm{~b}$ and $\mathrm{C} 3 \mathrm{dg}$. Each of these peptides acts as a ligand for specific receptor(s) to mediate classical C3-dependent functions such as opsonization, leukocyte chemotaxis and smooth muscle cell contraction (2). In the past few years, C3 has been also been found to play a role in the adaptive immune response. C3 has been shown to be necessary for an optimal antibody response to T-dependent antigens (3). Most C3 present in the serum is synthesized by the liver (4), but local synthesis by hematopoietically derived cells plays a more important role in immunomodulatory functions, since $\mathrm{C}^{-/-}$mice reconstituted with $\mathrm{C}^{+/+}$bone marrow are rescued from their impaired antibody response to $\mathrm{T}$ celldependent antigens (5). Extrahepatic synthesis of C3 occurs in macrophages, endothelial cells, and kidney tubular cells (2). Skin keratinocytes are also a rich source of $\mathrm{C} 3$, and $\mathrm{C} 3$ can be activated in the skin by mechanical and UV radiation injury (6-8).

Murine C3a is a 78-AA peptide derived from the $\mathrm{N}$-terminal end of C3 upon its activation by the classical, alternative, and lectin pathways $(9,10)$. Well-described functions of C3a include chemotaxis for mast cells (11) and eosinophils (12), and contraction of smooth

Nonstandard abbreviations used: atopic dermatitis (AD); epicutaneous (EC); intraperitoneal (i.p.); T cell receptor (TCR).

Conflict of interest: The authors have declared that no conflict of interest exists.

Citation for this article: J. Clin. Invest. 114:399-407 (2004).

doi:10.1172/JCI200419082. muscle cells (13). C3a performs these functions by engaging its receptor, $\mathrm{C} 3 \mathrm{aR}$, on target cells. $\mathrm{C} 3 \mathrm{aR}$ is a seven transmembrane $\mathrm{G}$ protein-coupled protein with structural resemblance to chemokine receptors (10). Expression of C3aR by human DCs (14), T cells (15), and $\mathrm{B}$ cells ( 3 ) suggests that the C3a-C3aR interactions might play a role in immune modulation. In fact, C3a has been shown to enhance IL- 6 release by human PBMCs stimulated with LPS or IL-1 $\beta$ (16), and to inhibit IgG and cytokine (IL-6, TNF- $\alpha$ ) synthesis by human B cells stimulated with Staphylococcus aureus and IL-2 (17). $\mathrm{C} \mathrm{aR}^{-/}$mice have increased IL-1 $\beta$ in the plasma and exhibit lethality in response to injection of LPS (18), suggesting that C3aR can act in vivo as an anti-inflammatory receptor by attenuating LPS-induced proinflammatory cytokine production. Following intraperitoneal (i.p.) sensitization, $\mathrm{C}_{3} \mathrm{aR}^{-/-}$mice and guinea pigs with a natural $\mathrm{C} 3 \mathrm{aR}$ defect exhibit diminished airway reactivity in response to airway challenge with antigen $(19,20)$. This is consistent with a role for C3a in airway smooth muscle contraction.

Following antigen stimulation, Th cells can develop into Th1 cells that secrete IFN- $\gamma$ or Th 2 cells that secrete IL-4, IL-5, and IL-13 (21). Cytokine microenvironment (22), antigen dose (23), affinity of antigens (24), MHC haplotypes and costimulatory factors (25) have all been implicated in Th1/Th2 polarization. DCs also play an important role in Th cell polarization. Based on their ability to favor Th1 or Th2 differentiation, mature DCs have been called DC1 or DC2 respectively (26). Production of IL-12 by DC1s favors the development of Th1 cells (27). Bacterial and viral products, and IFN- $\gamma$, which are potent stimuli for IL-12 secretion, result in DC1 and subsequent Th1 development, while PGE2, cholera toxin, and extracellular ATP are reported to favor DC2 differentiation (28-31).

We have developed a mouse model of atopic dermatitis (AD) using repeated epicutaneous (EC) sensitization with OVA to tape-stripped skin $(28,29)$. This model displays many of the features of human 
$\mathrm{AD}$ and results in a vigorous local and systemic Th2 response. This is evidenced by elevated total and antigen-specific IgE and a vigorous Th2 cytokine response of splenocytes to stimulation with the immunizing antigen. Mechanical injury to the skin by scratching is an important feature of $\mathrm{AD}$. C3a has been shown to accumulate in blisters induced by mechanical injury to the skin (8). This prompted us to assess the role of $\mathrm{C} 3 \mathrm{a}$ in the immune response induced by EC sensitization.

\section{Results}

$\mathrm{C} 3 a R^{-1-}$ mice have elevated serum IgG1 and decreased serum IgG2a levels. Analysis of thymocytes, bone marrow, and spleens revealed no detectable differences in cell numbers or distribution of lymphocyte subsets $\left(\mathrm{CD}^{+}, \mathrm{CD}^{+}, \mathrm{B}_{2} 20^{+}, \mathrm{IgM}^{+}, \mathrm{CD} 40^{+}\right)$between $\mathrm{C}^{2} \mathrm{aR}^{-/-}$ mice and WT littermates (data not shown). However, $\mathrm{C} 3 \mathrm{aR}^{-/-}$mice had significantly higher levels of IgG1 than WT littermates (Figure 1). In contrast, they had significantly lower IgG2a, IgG3, and IgA levels. Since the Th2 cytokines IL-4 and IL-13 play a critical role in isotype switching to IgG1, while the Th1 cytokine IFN- $\gamma$ plays a critical role in isotype switching to IgG2a, these results suggested that C3a may play an important role in Th cell polarization.

$\mathrm{C} 3 \mathrm{aR} \mathrm{R}^{-/}$mice mount an exaggerated $\mathrm{Th} 2$ response to EC sensitization with OVA antigen. Mechanical injury to the skin results in $\mathrm{C} 3$ activation and local generation of C3a (8). Since EC sensitization involves tape-stripping of the skin, which results in mechanical injury, we examined the effect of $\mathrm{C} 3 \mathrm{aR}$ deficiency on the immune response to epicutaneously introduced antigen. As we previously reported, WT BALB/C mice mounted OVA-specific IgG1, IgE, and IgG2a antibodies following EC sensitization (Figure 2), while no OVA-specific antibodies were detected in the sera of saline-sensitized mice. $\mathrm{C}^{3} \mathrm{aR}^{-1-}$ mice mounted significantly higher levels of OVA-specific IgG1 antibodies following EC sensitization than WT littermates. There were no significant differences in the levels of OVA-specific serum IgE or IgG2a levels between $\mathrm{C} \mathrm{aR}^{-/-}$and WT controls.

We next examined cytokine production in response to in vitro stimulation of splenocytes with OVA antigen. OVA stimulation of splenocytes from epicutaneously sensitized $\mathrm{BALB} / \mathrm{C}$ mice induced the secretion of IL-4, IL-5, and IL-10 (Figure 3). Splenocytes from OVA-sensitized C3aR ${ }^{-/-}$mice secreted significantly higher levels of IL-4, IL-5, and IL-10 in response to OVA. There was no induction of IFN- $\gamma$ secretion in vitro by splenocytes of epicutaneously sensitized WT or $\mathrm{C}^{2} \mathrm{aR}^{-/-}$mice. The increased secretion of Th2 cytokines was specific to the immunizing antigen, because the levels of IL-4, IL-5, and IL-10, as well as of IFN- $\gamma$, secreted by splenocytes following stimulation with anti-CD3 was comparable in $\mathrm{C}_{3} \mathrm{aR}^{-/-}$mice and WT controls (data not shown). Taken together, these results suggest that interaction of $\mathrm{C} 3 \mathrm{a}$ with its receptor $\mathrm{C} 3 \mathrm{aR}$ inhibits $\mathrm{Th} 2$ cell differentiation in response to epicutaneously introduced antigen.

\section{Figure 1}

Baseline levels of serum immunoglobulin isotypes in $\mathrm{C} \mathrm{aR}^{-1-}$ and $\mathrm{WT}$ littermates. ${ }^{*} P<0.05$; ${ }^{\star \star} P<0.01$.
Dermal infiltration with eosinophils and expression of Th2 cytokines are an important feature of our model. We also examined Th1 and Th 2 cytokine expression in the skin. There was no difference in the numbers of eosinophils in saline-treated skin of $\mathrm{C}_{3} \mathrm{aR}^{-/}$ and WT mice. OVA sensitization elicited a significantly stronger eosinophil influx in OVA-sensitized skin of $\mathrm{C}^{3} \mathrm{aR}^{-/-}$compared with WT controls (Figure 4A). There was negligible IL-4 mRNA expression in saline-sensitized skin of both $\mathrm{C}^{3} \mathrm{aR}^{-/-}$mice and WT controls. OVA-sensitized skin sites of $\mathrm{C} \mathrm{aR}^{-/-}$mice exhibited a trend towards higher IL-4 mRNA expression compared with WT controls, but the difference was not statistically significant (Figure 4B). There was no significant increase in skin IFN- $\gamma$ mRNA levels between saline- and OVA-sensitized sites in either WT or C3aR $-/-$ mice, and the IFN- $\gamma$ mRNA levels were similar in both strains.

C3a $\mathrm{R}^{-/-}$mice do not exhibit a deviated Th response to i.p. immunization with OVA antigen. We next examined whether the effect of C3aR deficiency on the Th response was selective to the EC route of immunization. To this end, we examined the response of $\mathrm{C}_{3} \mathrm{aR}^{-1-}$ mice to i.p. immunization with OVA in alum, a mode of immunization that also elicits an immune response with a strong Th2 component. There were no significant differences in the serum OVA-specific IgG1, IgE or IgG2a antibody levels of intraperitoneally immunized

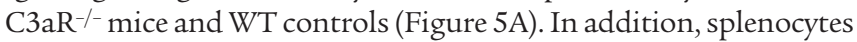
from intraperitoneally immunized $\mathrm{C}_{3} \mathrm{aR}^{-/-}$mice and WT controls produced similar levels of IL-4, IL-5, IL-10, and IFN- $\gamma$ when stimulated by OVA in vitro (Figure 5B).

We considered the possibility that the antigen dose used for immunization and in vitro antigen stimulation might have resulted in maximal Th2 cytokine production by intraperitoneally immunized mice. This could have prevented the detection of an enhanced Th2 response in intraperitoneally immunized $\mathrm{C}_{3} \mathrm{aR}^{-/-}$ mice. For this reason, we used an i.p. immunization protocol that consisted of two rather than three injections of antigen (on days 0 and 14) and stimulated the splenocytes in vitro with a range
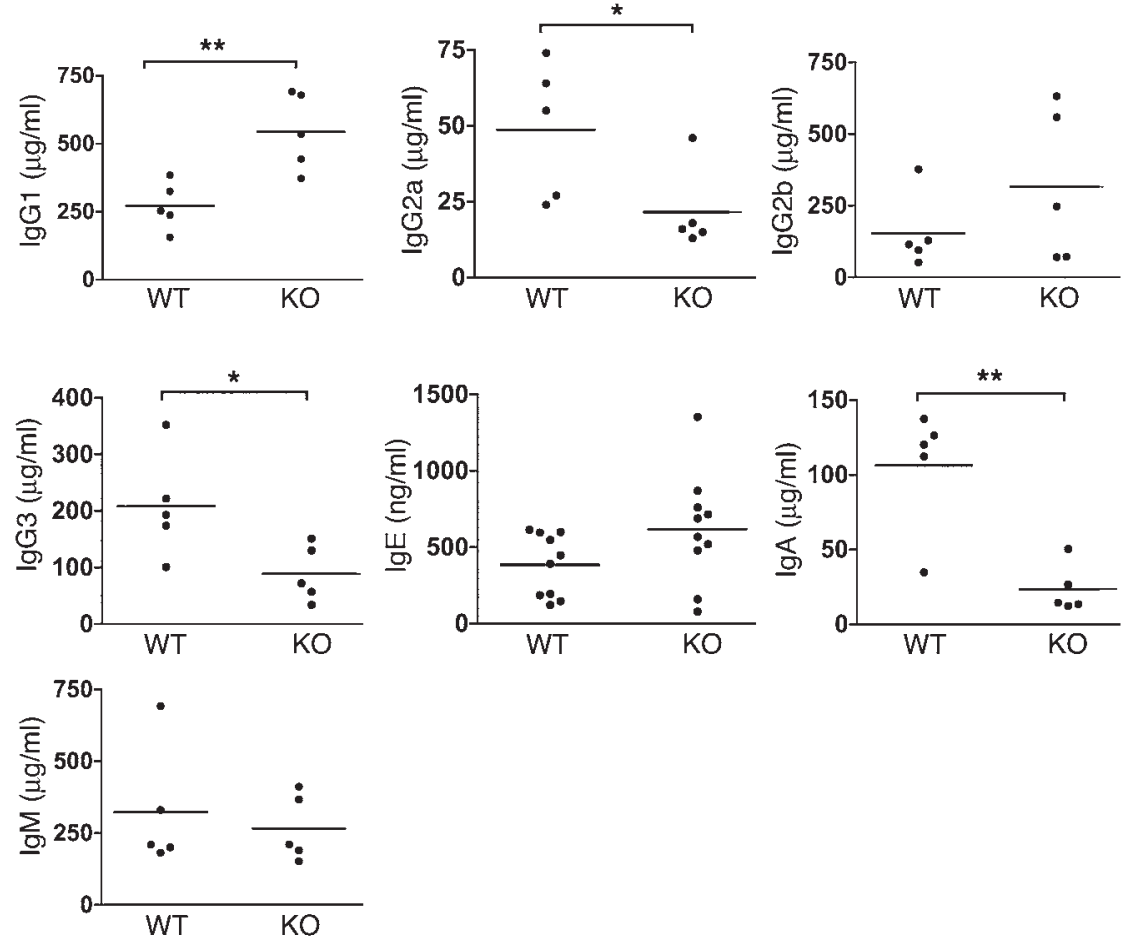

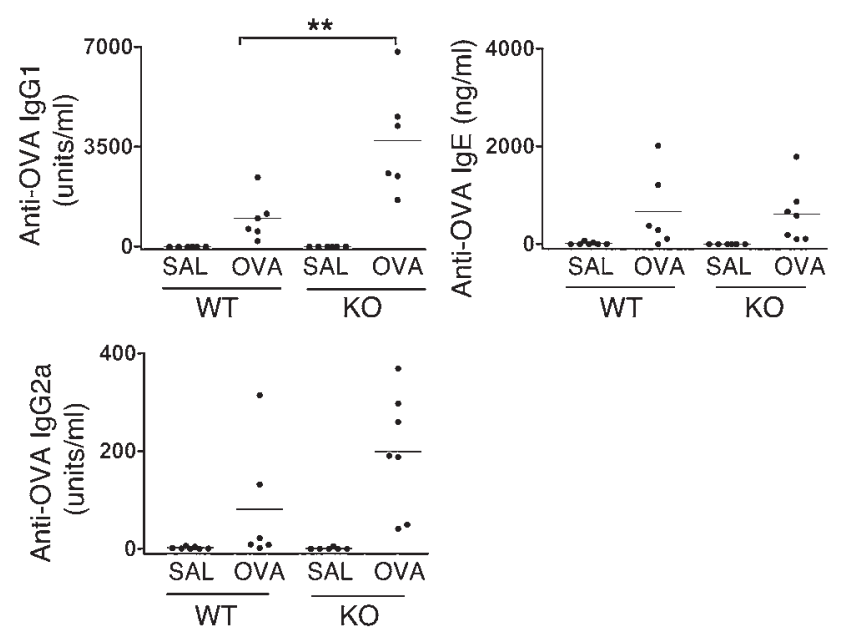

Figure 2

Serum levels of IgG1, IgE, and IgG2a anti-OVA antibodies in epicutaneously immunized ${\mathrm{C} 3 a R^{-1-}}^{-}$and WT littermates. Horizontal lines represent means. ${ }^{* \star} P<0.01$. SAL, saline-sensitized group; OVA, OVA-sensitized group.

of OVA concentrations (5 to $50 \mu \mathrm{g} / \mathrm{ml}$ ). Figure $5 \mathrm{C}$ shows that even under conditions in which Th2 cytokine secretion by WT splenocytes was suboptimal, there was no difference in cytokine secretion by splenocytes of $\mathrm{C}_{3} \mathrm{aR}^{-1-}$. These results suggest that the effect of $\mathrm{C} 3 \mathrm{aR}$ deficiency on the Th2 response to antigen is selective to the $\mathrm{EC}$ route of immunization.

APCs from $\mathrm{C} 3 a \mathrm{R}^{-1-}$ mice enhance the secretion of Th2 cytokines by OVA transgenic T cells. We directly examined the effect of C3aR deficiency on the ability of APCs to drive Th cell differentiation. Irradiated splenocytes from $\mathrm{C} \mathrm{aR}^{-/-}$mice and WT littermates on a BALB/ $\mathrm{C}$ background were used to present $\mathrm{OVA}_{323-339}$ peptide to highly purified $\mathrm{T}$ cells obtained from DO11.10 T cell receptor (TCR) transgenic mice on the same genetic background. Presentation of OVA peptide to the T cells by $\mathrm{C} \mathrm{aR}^{-/-}$APCs resulted in significantly higher IL-4 and IL-5 secretion compared with presentation by WT APCs (Figure 6). C3aR-1- APCs and WT APCs elicited equivalent amounts of IFN- $\gamma$ secretion by OVA-TCR transgenic T cells. These results suggest that the effect of $\mathrm{C} 3 \mathrm{a}-\mathrm{C} 3 \mathrm{aR}$ interactions on Th cell polarization is exerted, at least in part, at the level of the APCs.

C3a inhibits Th2 responses in vitro. Taken together, the above results suggest that $\mathrm{C} 3 \mathrm{a}-\mathrm{C} 3 \mathrm{aR}$ interactions inhibit $\mathrm{Th} 2$ responses, with no detectable effect on Th1 responses. We directly examined the effect of C3a on the development of Th cells in vitro following stimulation of splenocytes with anti-CD3. Since C3 may be secreted by APCs, we used splenocytes from $\mathrm{C}^{-/-}$mice to obviate the potential confounding effect of endogenously generated C3a. C3a by itself did not induce cytokine secretion (data not shown). Addition of C3a to anti-CD3-stimulated cells significantly inhibited the secretion of IL-4 and IL-13 in a dose-dependent manner (Figure 7A). In contrast, it had no effect on the secretion of IFN- $\gamma$. These results are consistent with the idea that C3a-C3aR interactions normally inhibit Th2 cytokine secretion but do not affect Th1 cytokine secretion.

Since both APCs and T cells may express C3aR $(14,15,30,31)$, we examined the effect of $\mathrm{C} 3 \mathrm{a}-\mathrm{C} 3 \mathrm{aR}$ interactions on the secretion of Th2 cytokines by highly purified $\mathrm{T}$ cells in response to antiCD3 and anti-CD28. C3a had no effect on Th2 cytokine production by these cells (Figure 7B). The inhibitory effect of C3a on
Th2 cytokine secretion by T cells stimulated with anti-CD 3 in the presence of APCs may have been exerted at the induction phase or on cells after they differentiated into Th2 cells. To distinguish between these two possibilities, we examined the effect of C3a on Th2 cytokine secretion by $\mathrm{T}$ cells that had been previously skewed to Th2 by stimulating TCR-OVA transgenic T cells with OVA in the presence of IL-4 and anti-IL-12. Figure 7C shows that addition of $10 \mathrm{nM} \mathrm{C} 3 \mathrm{a}$, a concentration that virtually completely inhibited IL-4 and IL-13 synthesis by naive T cells, had no effect on the secretion of these cytokines by differentiated Th2 cells. Furthermore, $\mathrm{C} 3 \mathrm{a}$ had no effect on IFN- $\gamma$ secretion by TCR-OVA transgenic T cells skewed to Th1 by previous stimulation with OVA in the presence of IL-12 and anti-IL-4.

C3a inbibition of the IL-4 production is mediated by IL-12. Taken together, the above results suggest that $\mathrm{C} 3 \mathrm{a}-\mathrm{C} 3 \mathrm{aR}$ interactions modulate Th2 cytokine secretion by targeting the APCs and not the T cell. To examine whether this inhibition is mediated by cell-to-cell contact or by secreted factors, we prepared splenic DCs from BALB/C mice by positive magnetic selection with anti-CD11c. The resulting population was more than $80 \% \mathrm{CD} 11 \mathrm{c}^{+}$. DCs were preincubated for 24 hours with human $\mathrm{C} 3 \mathrm{a}(10 \mathrm{nM})$. This concentration of C3a inhibited IL-4 secretion by TCR-OVA DO11.10 transgenic T cells stimulated with OVA peptide in the presence of DCs by $60-75 \%$ and did not affect IFN- $\gamma$ secretion by these cells. Supernatants from C3a-stimulated DCs and from control DCs incubated with medium were collected, and the cells were washed. Control supernatants collected were reconstituted with $\mathrm{C} 3 \mathrm{a}$, and all supernatants were passaged through a filter with a cutoff of $10 \mathrm{kDa}$. ELISA assay revealed depletion of more than $90 \%$ of the C3a. Figure 8A shows that DCs pretreated with $\mathrm{C} 3 \mathrm{a}$ did not differ from control DCs in their ability to support IL-4 and IFN- $\gamma$ secretion by DO11.10 T cells. In contrast, supernatants from DCs pretreated with C3a, but not control
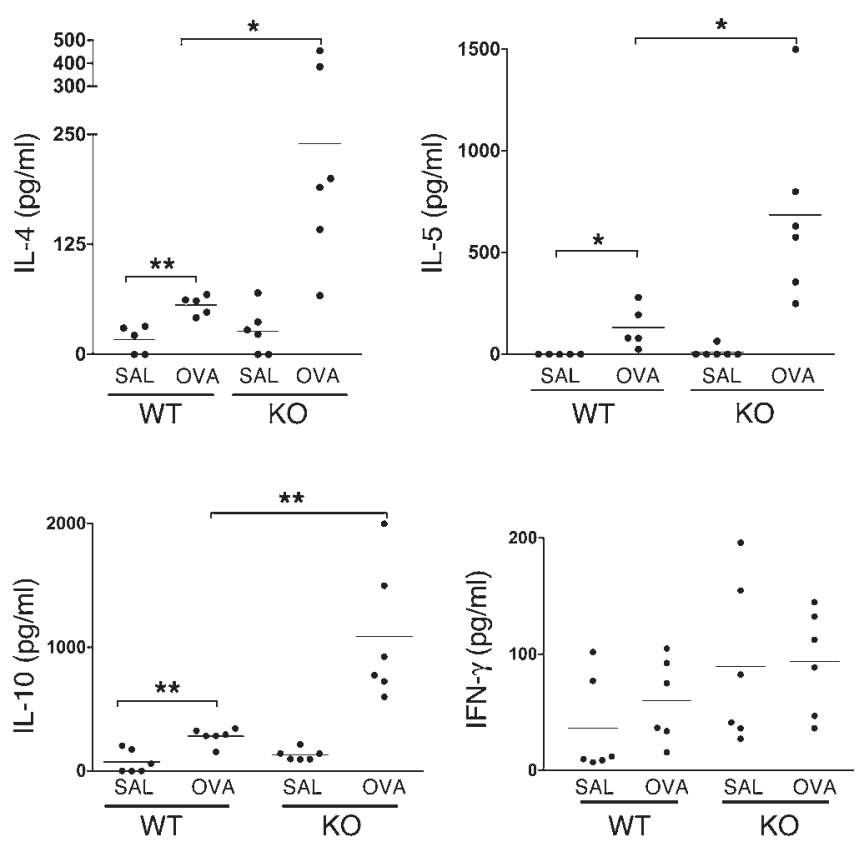

\section{Figure 3}

Cytokines in supernatants of splenocytes from epicutaneously sensitized $\mathrm{C}_{3} \mathrm{aR}^{-/-}$mice and WT littermates following in vitro stimulation with OVA. Horizontal lines represent means. ${ }^{\star} P<0.05,{ }^{\star *} P<0.01$. 
A

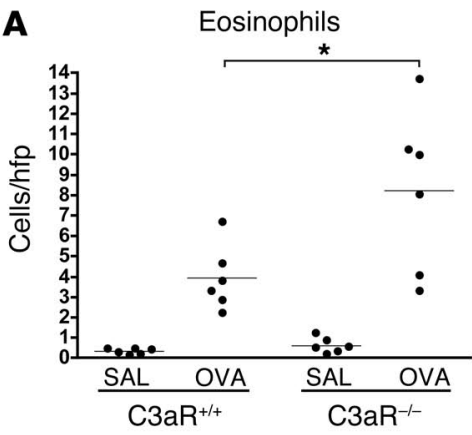

B

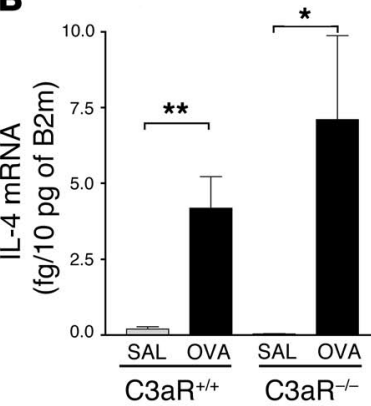

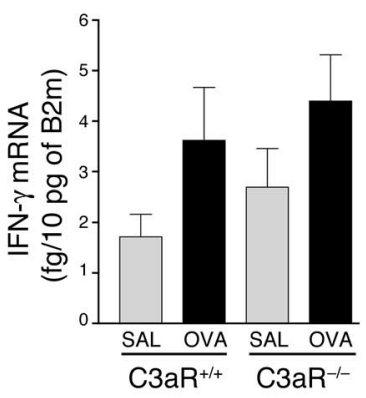

Figure 4

(A) Number of infiltrating eosinophils and (B) cytokine expression in sensitized skin of $\mathrm{C}_{3} \mathrm{aR}^{-/-}$mice and WT controls. Levels were normalized to $\beta 2$-microglobulin. Pooled results of experiments using 6 OVA-sensitized mice and six saline-sensitized controls. Horizontal lines represent mean \pm SEM. ${ }^{*} P<0.05,{ }^{* *} P<0.01$. hpf, high-power field. supernatants, inhibited IL-4, but not IFN- $\gamma$ secretion, by DO11.10 T cells stimulated with OVA peptide presented by fresh DCs (Figure $8 \mathrm{~B})$. The inhibition of IL-4 by the supernatants was dose dependent (Figure $8 \mathrm{C}$ ). These results suggest that C3a induces DCs to secrete a soluble factor that selectively inhibits Th2 cytokine production.

IL-12 is a Th2-inhibitory cytokine secreted by DCs (32). We therefore examined whether IL-12 could be the IL-4-inhibitory factor secreted by C3a-stimulated DCs. Figure 9A shows that stimulation with C3a triggered IL-12 p70 secretion by splenic CD $11 \mathrm{c}^{+}$ $\mathrm{DCs}$ from $\mathrm{BALB} / \mathrm{c}$ mice. To test whether IL-12 is involved in the IL-4-inhibitory activity of supernatants from C3a-treated DCs, the supernatants were first depleted of $\mathrm{C} 3 \mathrm{a}$ by ultrafiltration, then immunodepleted of IL-12 by anti-p40 and anti-p35 immunoaffinity chromatography, and tested as above. Depletion with either anti-p40 or with anti-p35 mAb, but not with IgG isotype controls, abrogated their ability to inhibit IL-4 secretion by T cells (Figure 9B). To further confirm the involvement of IL-12 in our system, we tested whether supernatants from C3a-stimulated DCs from p $40^{-/-}$and $\mathrm{p} 35^{-/-}$mice were capable of inhibiting IL-4 secretion by TCR-OVA transgenic T cells. Supernatants of C3a-treated DCs from both $\mathrm{p}^{40^{-/}}$and $\mathrm{p} 35^{-/-}$mice failed to suppress IL-4 secretion by DO11.10 T cells (Figure 9C). Taken together, these results suggest that IL-12 secreted by DCs in response to stimulation with C3a plays an essential role in the inhibition of IL-4 production.

\section{Discussion}

The present study shows that absence of $\mathrm{C} 3 \mathrm{aR}$ results in an exaggerated Th2 response to epicutaneously introduced antigen. This effect is exerted, at least in part, at the level of APCs.

The immune system of $\mathrm{C} \mathrm{aR}^{-1-}$ mice has not previously been well characterized. Our results show that $\mathrm{C}_{3} \mathrm{aR}^{-/-}$mice have normal numbers and subset distribution of $\mathrm{T}$ and $\mathrm{B}$ lymphocytes in their lymphoid organs, suggesting that $\mathrm{C} 3 \mathrm{a}-\mathrm{C} 3 \mathrm{aR}$ interactions are not important for $\mathrm{T}$ and $\mathrm{B}$ cell development. However, we found significantly increased levels of serum IgG1 and decreased serum IgG2a, IgG3, and IgA in $\mathrm{C} \mathrm{aR}^{-/-}$mice compared with WT littermate controls. The Th2 cytokine IL-4 is essential for normal IgG1 isotype switching, while the Th1 cytokine IFN- $\gamma$ is important for IgG2a switching (33). The elevated IgG1 and decreased IgG2a levels in $\mathrm{C}^{3} \mathrm{aR}^{-1-}$ mice suggest that the immune response of these mice to normally encountered environmental antigens is skewed towards Th2. The fact that baseline IL- 4 and IFN- $\gamma$ production were low and not significantly different in OVA-immunized WT and $\mathrm{C} 3 \mathrm{aR}^{-/-}$mice may simply reflect the fact the frequency of cytokine-producing OVA-specific T cells may not be sufficient to result in a difference in cytokine production by total splenocytes. In vitro stimulation with antigen that results in expansion of these cells is required to give rise to detectable differences. IL-4 inhibits IgA synthesis by B cells from both normal and atopic subjects

\section{Figure 5}

(A) Serum levels of $\lg E, \lg G 1$, and IgG2a anti-OVA antibodies in intraperitoneally immunized $\mathrm{C}_{3} \mathrm{aR}^{-/-}$ and WT littermates. Horizontal lines represent means. (B and $\mathbf{C}$ ) Cytokines in supernatants of splenocytes from i.p-immunized $\mathrm{C}_{3} \mathrm{aR}^{-/-}$mice and WT littermates following in vitro stimulation (stim.) with OVA. Pooled results of experiments using five or six mice in each group. Vertical lines and error bars represent mean \pm SEM.
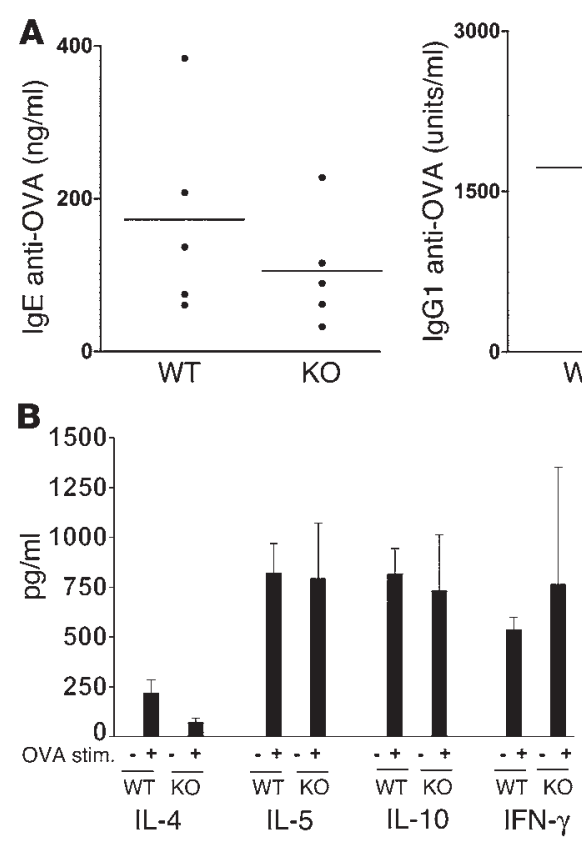
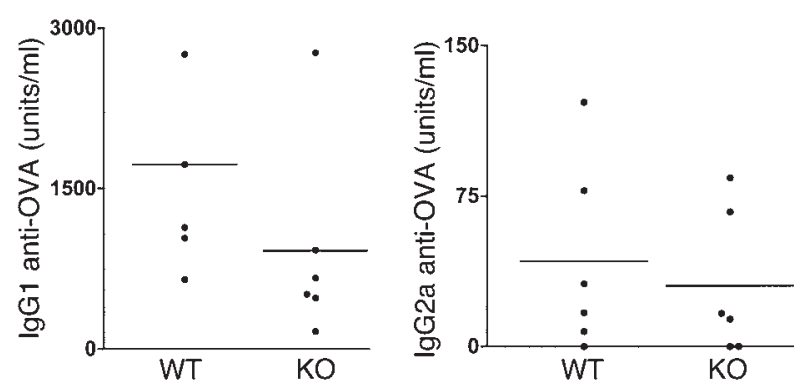

C

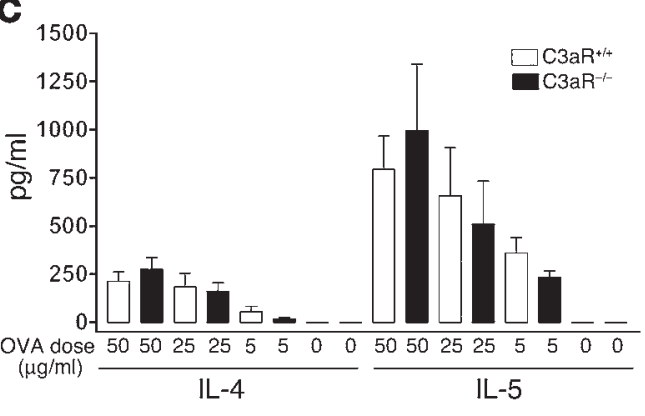



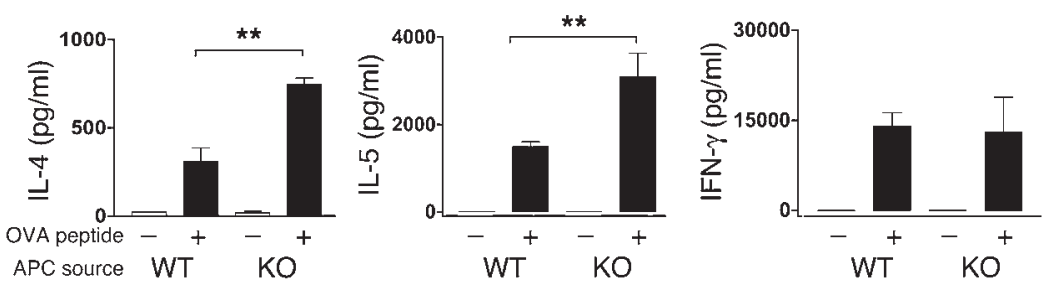

\section{Figure 6}

Cytokine production by splenic T cells from TCR-OVA transgenic mice stimulated in vitro with APCs from $\mathrm{C} \mathrm{aR}^{-1-}$ mice and WT controls in the presence or absence of $\mathrm{OVA}_{323-339}$ peptide. Bars and error bars represent mean \pm SEM of three experiments. ${ }^{* *} P<0.01$.

$(34,35)$. Increased IL-4 production may underlie the decreased IgA in $\mathrm{C}_{3} \mathrm{aR}^{-/}$mice. Studies in $\mathrm{TACI}^{-/-}$mice and $\mathrm{APRIL}^{-/-}$mice $(36,37)$ suggest that BAFF/APRIL, which are expressed on DCs, are critical for normal serum IgA and for IgA isotype switching in vivo in response to mucosal immunization. Since C3a modulates IL-12 production by DCs, it will be important to test whether it also modulates their BAFF/APRIL expression. The fact that serum IgE was not elevated in $\mathrm{C} \mathrm{aR}^{-/}$mice may reflect the tight control of IgE synthesis by Th1 cytokines such as IFN- $\gamma$, the production of which is not decreased in $\mathrm{C} 3 \mathrm{aR}^{-/-}$mice.

Keratinocytes are a rich source of C3 (38-40), and trauma to the skin has been shown to result in the generation of C3a (8). Epicutaneously immunized $\mathrm{C}_{3} \mathrm{aR}^{-/-}$mice had a significantly increased OVA-specific IgG1 antibody response. More importantly, their splenocytes secreted significantly increased amounts of the Th2 cytokines IL-4, IL-5, and IL-10 in response to in vitro stimulation with OVA, although cells other than Th2 cells, for example regulatory $\mathrm{T}$ cells, may have contributed to increased IL-10 production. There was significantly increased infiltration with eosinophils and a trend towards increased expression of IL-4 mRNA in epicutaneously immunized skin sites of $\mathrm{C}_{3} \mathrm{aR}^{-/-}$mice. The fact that the IL-4 mRNA increase was not significant, in the face of a significant increase in Th2 cytokine secretion by splenocytes, suggests that local factors limit the infiltration of Th2 cells and/or the expression of Th2 cytokines in the skin.

EC immunization results in a weak Th1 response with low antigen-specific IgG2a levels (28), and no detectable induction of IFN- $\gamma$ secretion in antigen-stimulated splenocytes (41). The IgG2a anti-OVA response of $\mathrm{C} 3 \mathrm{aR}^{-/-}$mice to EC immunization was comparable to that of WT BALB/C controls. Furthermore, splenocytes from epicutaneously immunized $\mathrm{C} 3 \mathrm{aR}^{-/-}$mice and WT controls failed to secrete IFN- $\gamma$ in response to in vitro stimulation with OVA. The reason why serum IgE and

\section{Figure 7}

Effect of $\mathrm{C} 3 \mathrm{a}$ on in vitro cytokine production by splenocytes from $\mathrm{C}^{-/-}$mice stimulated with anti-CD3 $(\mathbf{A})$, by splenic T cells from $\mathrm{C}^{-/-}$mice stimulated with anti-CD3 and anti-CD28 (B) and by DO11.10 TCROVA transgenic $T$ cells that had been differentiated under Th2 or Th1 conditions (C). A single concentration of C3a (10 nM) was used in experiment $C$. ${ }^{*} P<0.05$ (unpaired Student's $t$ test). Vertical lines and error bars represent mean \pm SEM of five experiments in $\mathbf{A}$ and $\mathbf{B}$ and three experiments in $\mathbf{C}$.
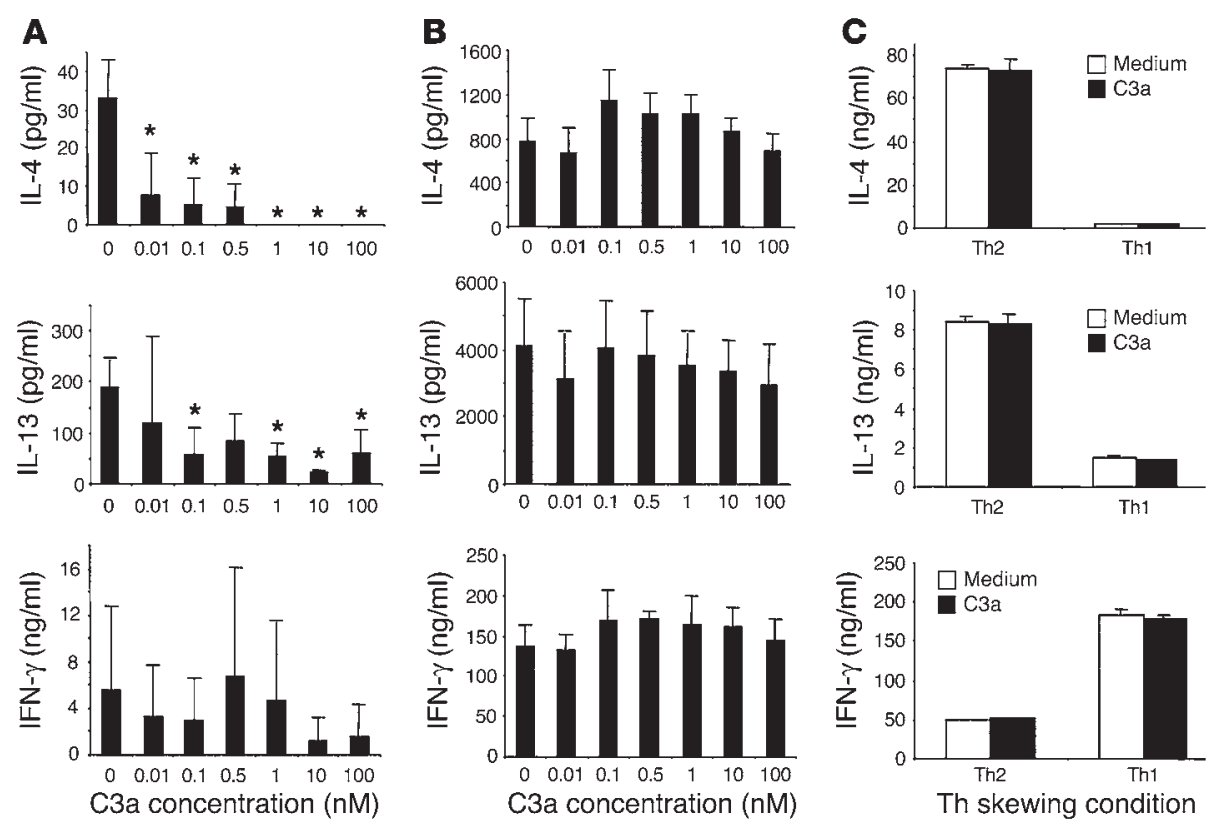
A
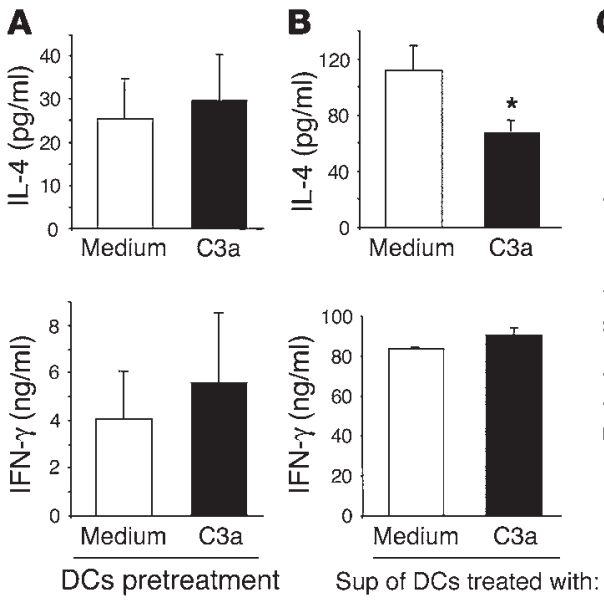

C

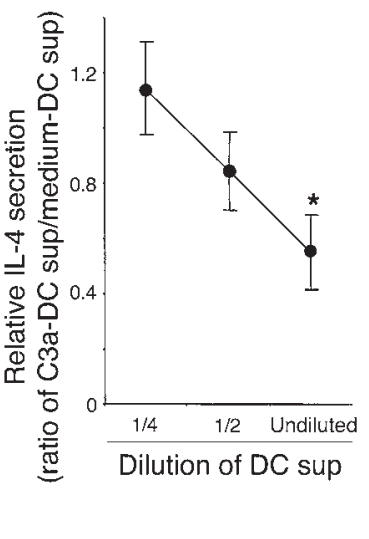

\section{Figure 8}

(A) Effect of pretreatment of BALB/C splenic DCs with C3a on their ability to support cytokine production by DO11.10 TCR-OVA transgenic T cells in response to OVA peptide. (B) Effect of supernatants of splenic DCs treated with $\mathrm{C} 3 \mathrm{a}$, then depleted of $\mathrm{C} 3 \mathrm{a}$, on cytokine production by DO11.10 TCROVA transgenic $T$ cells in response to OVA peptide presented by fresh DCs. Columns and error bars represent mean \pm SEM of three experiments. ${ }^{*} P<0.05$. (C) Dose-response analysis of the effect of supernatants from C3a-stimulated DCs on IL-4 secretion. Sup, supernatant. peritoneal macrophages have been reported to secrete a monocarboxypeptidase that inactivates $\mathrm{C} 3 \mathrm{a}$ (43). Finally, we cannot rule out a differential effect of $\mathrm{C} 3 \mathrm{a}$ on skin versus peritoneal APCs.

The normal systemic Th cell response of $\mathrm{C} \mathrm{aR}^{-1-}$ mice to i.p. immunization is consistent with our previous observation that intraperitoneally immunized $\mathrm{C} 3 \mathrm{aR}^{-/-}$mice on a BALB/C background develop normal BAL eosinophilia and a normal BAL cytokine response following antigen inhalation challenge (19). It was recently reported that $\mathrm{C}^{3} \mathrm{aR}^{-/-}$mice on a C57BL6 background immunized intraperitoneally with a mixture of OVA and Aspergillus fumigatus extract have decreased OVA-specific IgE response and a diminished airway inflammatory response, with decreased numbers of cells that secrete Th2 cytokines in the lungs (44). Although cytokine production by antigen-stimulated spleen cells was not measured, the results suggested that C3aR deficiency inhibits Th2 cell development. The different results obtained in this study and in ours may relate to differences in antigen preparation, genetic background, and route of immunization. The gut and airways are usually major portals of normal antigen encounter. Given the fact that $\mathrm{C} \mathrm{aR}^{-/-}$mice had increased levels of serum IgG1 and IgE and decreased serum IgG2a, it will be important to examine in future studies the role of $\mathrm{C} 3 \mathrm{a}-\mathrm{C} 3 \mathrm{aR}$ interactions on the Th response to antigens absorbed through these portals.

We directly demonstrated that APCs that lack C3aR skew cytokine secretion by $\mathrm{T}$ cells towards Th2. In the presence of the cognate peptide, C3aR-/- APCs induced significantly more IL-4 and IL-5 secretion by OVA-TCR transgenic T cells than WT APCs. There

\section{Figure 9}

C3a inhibition of IL-4 production is mediated by IL-12. (A) C3a induces IL-12 p70 secretion by BALB/c splenic DCs. (B) Immunodepletion of IL-12 abrogates the IL-4-inhibitory activity of C3a-stimulated DC supernatants. Supernatant of C3a-stimulated DCs were first depleted of $\mathrm{C} 3 \mathrm{a}$, then subjected to immunoaffinity chromatography using protein G columns immobilized with anti-mouse IL-12 p40, anti-IL-12 p35 $\mathrm{mAb}$, or isotype controls, and then tested for inhibition of IL-4 production as detailed in Figure 8B. (C) Impaired IL-4-inhibitory activity of C3a-stimulated DC supernatant from IL-12-deficient mice. C3astimulated splenic DC supernatants from IL-12 p40---, p35-/-, or WT C57BL/6 mice were tested for inhibition of IL-4 production as detailed in Figure 8B. Columns and error bars represent mean \pm SEM of three experiments. ${ }^{*} P<0.05$. was no detectable difference in the ability of $\mathrm{C}^{2} \mathrm{aR}^{-/-}$and WT APCs to support IFN- $\gamma$ secretion by the transgenic T cells. These results strongly suggest that $\mathrm{C} 3 \mathrm{a}$ interaction with its receptor on APCs normally regulates their ability to induce Th2 cell differentiation.

Addition of C3a inhibited in a dose-dependent manner the capacity of splenocytes from C3-/- mice to secrete the Th2 cytokines IL-4 and IL-13 in response to anti-CD3 stimulation but had no effect on the secretion of the Th1 cytokine IFN- $\gamma$. This directly demonstrates that C3a inhibits Th2 cytokine production. C3a inhibit-

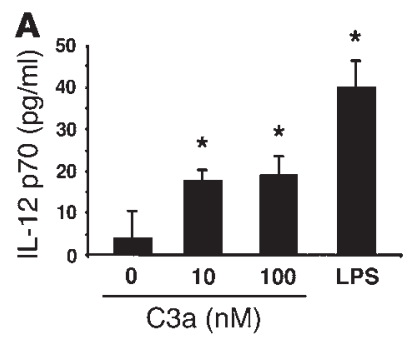

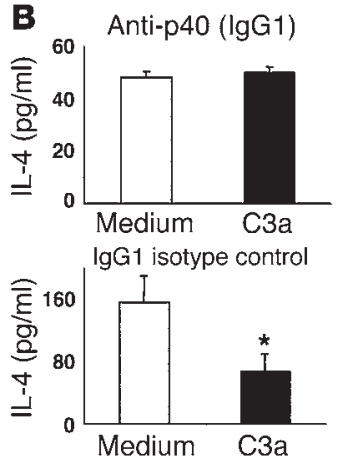

Sup of DCs treated with:

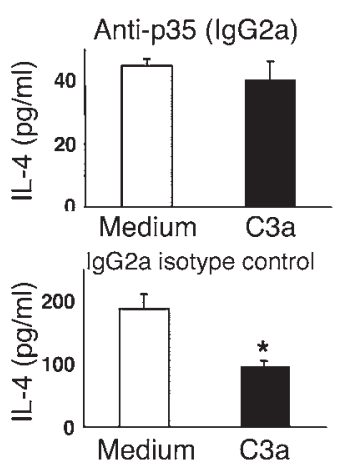

Sup of DCs treated with:
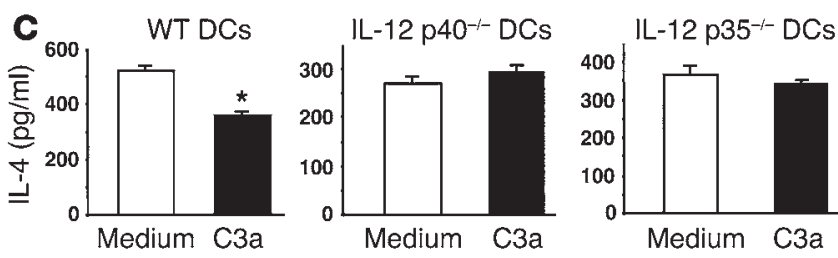

Sup of DCs treated with: 
ed Th2 cytokine production at concentrations well below those reported to accumulate in skin blister fluids following mechanical injury (8). The inhibitory effect of C3a on Th2 cytokine secretion was likely exerted at the induction phase because C3a had no effect on cytokine secretion by differentiated Th2 cells. C3a had also no effect on Th2 cytokine production by purified $\mathrm{T}$ cells stimulated with anti-CD3 and anti-CD28. This suggested that the inhibitory action of C3a was exerted primarily at the level of the APCs rather than on T cells.

Experiments using C3a-treated DCs and their supernatants suggest that the inhibitory effect of $\mathrm{C} 3 \mathrm{a}$ on Th2 cytokine secretion is mediated by a soluble factor secreted by C3a-stimulated DCs rather than by cell-to-cell contact between C3a-treated DCs and $\mathrm{T}$ cells. We have identified this factor as IL-12. C3a induced IL-12 release from purified DCs. More importantly, immunodepletion of supernatants with anti-p40 and anti-p35 mAbs abrogated their IL-4-inhibitory activity. Finally, DCs from p35- and p40-deficient mice did not release IL-4-inhibitory activity in response to C3a. Because p40 is a shared subunit of IL-12 and IL-23 (7), we cannot rule out a contribution of IL-23 in concert with IL-12 to the IL-4-inhibitory activity in supernatants of DCs stimulated with C3a. A recent report shows that human DCs fail to secrete IL-12 after C3a stimulation (45) In contrast to our freshly isolated DCs, these human DCs were derived from PBMCs stimulated with IL-4+GM-CSF. Their failure to secrete IL-12 in response to C3a may be due to species differences, a different level of C3aR expression, or prior treatment with IL-4+GM-CSF.

While EC application of antigen normally induces a strong Th2 response in WT mice, the fact that $\mathrm{C}_{3} \mathrm{aR}^{-/-}$mice had an even more exaggerated Th2 response after EC sensitization suggests that there are factors released during skin injury that favor a Th2 response and that other factors, such as $\mathrm{C} 3 \mathrm{a}$, counterbalance this effect. Following EC immunization, antigen-laden skin DCs take up antigen, express receptors for CCR7, downregulate E-cadherin, and secrete metalloproteinases (43). This allows them to migrate to regional lymph nodes in response to the chemokine, secondary lymphoidtissue chemokine (46), where they encounter antigen-specific $\mathrm{T}$ cells. Local factors released in the skin in response to injury include iC3b (6), PGE2 (47), and IL-10 (48). All three factors are known to downregulate IL-12 production by DCs and to induce DCs to drive the differentiation of Th 2 cells. Our results suggest that, by promoting IL-12 production, C3a interaction with its receptor on skin DCs counterbalances these Th2-inductive signals and limits the ability of the DCs to drive Th2 cell differentiation.

C3a-C3aR interactions play a critical role in the effector phase of asthma as evidenced by the diminished airway hyperresponsiveness to OVA inhalation of $\mathrm{C} \mathrm{aR}^{-/-}$mice immunized intraperitoneally with OVA (19). Given the strong evidence that EC exposure to antigens plays an important role in AD (47), our present observations suggest that $\mathrm{C} 3 \mathrm{a}-\mathrm{C} 3 \mathrm{aR}$ interactions play a role in AD. Furthermore, they raise the possibility that mutations in this ligand receptor pair may exist in some patients with AD. Furthermore, our findings have important implications for devising therapies that interfere with the development of a Th2 response following EC antigen exposure.

\section{Methods}

Mice and sensitization. $\mathrm{C} 3 \mathrm{aR}^{-/-}$mice were generated as described and have been bred for nine generations on a BALB/C background (19). Age- and weight-matched littermates were used as WT controls. The animals were kept in a specific pathogen-free environment. All procedures performed on the animals were in accordance with the Animal Care and Use Committee of the Children's Hospital, Boston, USA.

EC sensitization of 4- to 6-week-old female mice was performed as described previously (28). Briefly, the skin of anesthetized mice was shaved and tape-stripped six times by transparent IV dressing (Tegaderm; Owens $\&$ Minor Inc., Franklin, Massachusetts, USA). One hundred micrograms of chicken egg OVA (OVA Grade V; Sigma-Aldrich, St Louis, Missouri, USA) in $100 \mu \mathrm{l}$ of normal saline, or placebo ( $100 \mu \mathrm{l}$ of normal saline), was placed on a patch of sterile gauze $(1 \times 1 \mathrm{~cm})$, which was secured to the skin with a transparent bio-occlusive dressing. Each mouse had a total of three 1-week exposures to the patch separated from each other by 2-week intervals. For i.p. immunization, mice were injected with $50 \mu \mathrm{g}$ OVA in alum on days 0 , 14 , and 21 and were killed on day 28.

Flow cytometry analysis. Single cell suspensions were stained with FITCor phycoerythrin- conjugated (PE-conjugated) antibodies in PBS containing 5\% rat serum (Sigma-Aldrich), $0.05 \%$ sodium azide, and Fc-block (BD - Pharmingen, San Diego, California, USA), washed, fixed in $2 \%$ paraformaldehyde, and analyzed on a FACSCalibur cytometer (BD, Mountain View, California, USA). FITC- or PE-conjugated mAbs used in these studies were: CD3 (145-2C11), CD4 (L3T4), CD8 $\alpha$ (53-6.7), B220 (RA3-6B2), anti-CD40 (3/23), and anti-IgM (R6-60.2) (all from BD - Pharmingen.

Serum immunoglobulins and antibody determinations. The BD - Pharmingen protocol for sandwich ELISA was used to quantify serum immunoglobulins. Specific IgG1, IgG2a, and IgE anti-OVA antibodies were determined by ELISA following the procedures we previously described (28).

In vitro cytokine synthesis. Single-cell suspensions of spleen cells were prepared in complete RPMI 1640 (JRH Biosciences Inc., Lenexa, Kansas, USA) supplemented by $10 \% \mathrm{FCS}, 1 \mathrm{mM}$ sodium pyruvate, $2 \mathrm{mM}$ L-glutamine, $0.05 \mathrm{mM} 2-\mathrm{ME}, 100 \mathrm{U} / \mathrm{ml}$ penicillin, and $100 \mu \mathrm{g} / \mathrm{ml}$ streptomycin. Cells were cultured in the above medium at $2 \times 10^{6} / \mathrm{ml}$ in 24-well plates in the

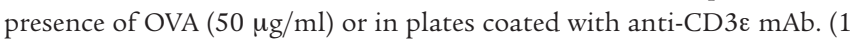
$\mu \mathrm{g} / \mathrm{ml}$; BD - Pharmingen). Supernatants were collected after 96 hours of culture, centrifuged, and frozen until use. IL-4, IL-5, IL-10, and IFN- $\gamma$ in supernatants were determined by ELISA following the manufacturer's instructions (BD - Pharmingen).

Eosinophil infiltration and expression of cytokines in the skin. Skin biopsies obtained at the end of the third sensitization were fixed in 10\% buffered formalin and embedded in paraffin. Multiple 4- $\mu \mathrm{m}$ sections were stained with $\mathrm{H} \&$ E. Eosinophils were counted blinded in 15-20 high-power fields at a magnification of $\times 1000$. Biopsies were also immediately frozen in dry ice. RNA isolation, cDNA synthesis, and RT-PCR amplification and quantification of IL- 4 and IFN- $\gamma$ mRNA were as described previously (29). Results were expressed as a ratio of cytokine cDNA to $\beta 2$-microglobulin cDNA.

Cytokine secretion by T cells from OVA-specific TCR transgenic mice. T cells from spleens of TCR transgenic mice BALB/C-TgN(DO11.10)10Loh (Jackson Laboratories, Bar Harbor, Maine, USA) were purified over mouse T cell enrichment columns (R\&D Systems Inc., Minneapolis, Minnesota, USA) and consisted of $90-95 \% \mathrm{CD}^{+}$cells. APCs consisted of irradiated (2000 rad) splenocytes. T cells were cultured in 24 -well plates $\left(10^{6}\right.$ cells/well $)$ in the presence of APCs $\left(1.0 \times 10^{6}\right.$ irradiated cells/well $)$ obtained from either WT $\mathrm{BALB} / \mathrm{C}$ mice or $\mathrm{C}_{3} \mathrm{aR}^{-/-}$mice and were stimulated with $\mathrm{OVA}_{323-339}$ peptide $(0.5 \mu \mathrm{M})$ (Sigma-Aldrich, The Woodlands, Texas, USA). After 72 hours, supernatants were collected and assayed for cytokines by ELISA.

Effect of C3a on cytokine production. Splenocytes from C3\%- mice (3), a kind gift from M. Carroll (The CBR Institute for Biomedical Research Inc., Harvard Medical School, Boston, Massachusetts, USA), were cultured in 96-well plates in the presence of plate-bound anti-mouse CD $3 \varepsilon \mathrm{mAb}(1$ $\mu \mathrm{g} / \mathrm{ml})$. Highly purified $\mathrm{T}$ cells were obtained from spleens of $\mathrm{C}^{-/-}$mice as described above and cultured in 96-well plates in the presence of plate- 
bound anti-CD3e $(10 \mu \mathrm{g} / \mathrm{ml})$ and anti-CD28 mAb $(10 \mu \mathrm{g} / \mathrm{ml})$. Recombinant human C3a (Calbiochem-Novabiochem International Inc., San Diego, California, USA) was added to the wells at the beginning of the culture. Supernatants were collected after 72 hours of culture, centrifuged and frozen at $-20^{\circ} \mathrm{C}$ until cytokines were quantified by ELISA following the manufacturer's instructions (BD - Pharmingen).

Differentiation of T cells from OVA-specific TCR transgenic mice into Th2 and Th1 cells. Splenocytes $\left(2 \times 10^{5}\right.$ cells $)$ from OVA-specific TCR transgenic mice were stimulated with $\mathrm{OVA}_{323-339}$ peptide $(0.5 \mu \mathrm{M})$ for 72 hours under Th2 (10 ng/ml IL-4 and $10 \mu \mathrm{g} / \mathrm{ml}$ anti-IL-12; BD - Pharmingen) or Th1 (10 $\mathrm{ng} / \mathrm{ml} \mathrm{IL-12}$ and $10 \mu \mathrm{g} / \mathrm{ml}$ anti-IL-4) skewing conditions. After washing with medium, cells were restimulated with immobilized anti-CD3ع $(1 \mu \mathrm{g} /$ $\mathrm{ml})$ for 24 hours in the presence of $\mathrm{C} 3 \mathrm{a}(10 \mathrm{nM})$. Cytokines secreted into the supernatants were analyzed by ELISA as described above.

Effect of C3a on splenic DCs and preparation and assay of DCs supernatants. CD $11 \mathrm{c}^{+}$DCs were purified from BALB/c splenocytes by MACS (Miltenyi Biotec $\mathrm{GmbH}$, Bergisch Gladbach, Germany) with a purity of approximately $80 \%$. DCs $\left(2 \times 10^{6}\right.$ cells $)$ were pretreated with human C3a $(10 \mathrm{nM})$ for 24 hours in the presence of OVA peptide $(0.25 \mu \mathrm{M})$ and GM-CSF (10 $\mathrm{ng} / \mathrm{ml})$. The supernatants were collected, and the cells were washed twice and cocultured $\left(2 \times 10^{4} \mathrm{DCs}\right)$ with purified OVA-specific TCR transgenic $\mathrm{T}$ cells $\left(4 \times 10^{5}\right.$ cells $)$ for 72 hours. Supernatants of DCs cultured with medium and spiked with $\mathrm{C} 3 \mathrm{a}(10 \mathrm{nM})$ as well as supernatants from C3atreated DCs were depleted of C3a by ultrafiltration using NANOSEP $10 \mathrm{~K}$ OMEGA filter units (Pall Corp., Ann Arbor, Michigan, USA). The efficiency of C3a depletion by this protocol was more than $90 \%$ as assessed by ELISA using a kit from $\mathrm{BD}-$ Pharmingen with a lower sensitivity limit of $1 \mathrm{pM}$. OVA-TCR transgenic T cells $\left(4 \times 10^{5}\right.$ cells $)$ were then cultured in undiluted supernatants with freshly isolated BALB/C splenic DCs $\left(2 \times 10^{4}\right.$ cells $)$ and OVA peptide $(0.25 \mu \mathrm{M})$. After 72 hours culture, secreted cytokines were analyzed by ELISA.

Analysis and immunodepletion of IL-12 in supernatants of C3a-treated DCs. $\mathrm{BALB} / \mathrm{c}$ splenic CD11 $\mathrm{c}^{+}$DCs $\left(2 \times 10^{6}\right.$ cells $)$ were stimulated with human C3a $(10 \mathrm{nM})$ for 24 hours in the presence of GM-CSF $(10 \mathrm{ng} / \mathrm{ml})$. IL-12 secreted into the supernatants was analyzed by ELISA using kits from BD
- Pharmingen. To immunodeplete IL-12, C3a-depleted DC supernatant $(500 \mu \mathrm{l})$ was mixed with $25 \mu \mathrm{l}$ slurry of Protein G Sepharose (Amersham Biosciences AB, Uppsala, Sweden) bound with $5 \mu \mathrm{g}$ of rat anti-mouse IL-12 p40 (IgG1 isotype, BD - Pharmingen), or anti-IL-12 p35 (IgG2a; eBioscience, San Diego, California, USA) monoclonal antibody. After incubation for 2 hours at $4{ }^{\circ} \mathrm{C}$ with rotation, the C3a-treated DC supernatant was recovered by centrifugation and used to culture DO11.10 T cells as described above. For the control experiment, the DC supernatant was treated with protein $\mathrm{G}$ column immobilized with isotype control IgG1 or IgG2a antibody (BD - Pharmingen).

C3a-stimulated DC supernatant from IL-12-deficient mice. Supernatants of C3a-stimulated splenic CD11 $\mathrm{c}^{+}$DCs from IL-12 p40- or p35-deficient mice (C57BL/6 background; Jackson Laboratory) were prepared as described above and assessed for their effect on IL-4 secretion by DO11.10 T cells. WT C57BL/6 mice were purchased from Taconic (Germantown, New York, USA).

Statistical analysis. Student's $t$ test was used to compare the differences between groups. A $P$ value less than 0.05 was considered statistically significant.

\section{Acknowledgments}

We would like to express our gratitude to Harri Alenius for his technical assistance, Haifa Jabara for her critical review of the manuscript, and Richard Blumberg for useful discussions. This work was supported by USPHS Grant AR 47417. S. Kawamoto was supported by a postdoctoral fellowship for research abroad from the Japan Society for the Promotion of Science.

Received for publication May 30, 2003, and accepted in revised form June 1, 2004.

Address correspondence to: Raif S. Geha, Division of Immunology, Children's Hospital, One Blackfan Circle, Karp 10th Floor, Boston, Massachusetts 02115, USA. Phone: (617) 919-2482; Fax: (617) 730-0528; E-mail: raif.geha@tch.harvard.edu.

Seiji Kawamoto and Ali Yalcindag contributed equally to this work.
1. Ember, J.A., and Hugli, T.E. 1997. Complement factors and their receptors. Immunopharmacology. 38:3-15.

2. Carroll, M.C. 1998. The role of complement and complement receptors in induction and regulation of immunity. Annu. Rev. Immunol. 16:545-568.

3. Fischer, M.B., et al. 1996. Regulation of the B cell response to T-dependent antigens by classical pathway complement. I. Immunol. 157:549-556.

4. Alper, C.A., Johnson, A.M., Birtch, A.G., and Moore, F.D. 1969. Human C'3: evidence for the liver as the primary site of synthesis. Science. 163:286-288.

5. Fischer, M.B., Ma, M., Hsu, N.C., and Carroll, M.C. 1998. Local synthesis of C3 within the splenic lymphoid compartment can reconstitute the impaired immune response in C3-deficient mice. J. Immunol. 160:2619-2625.

6. Yoshida, Y., et al. 1998. Monocyte induction of IL-10 and down-regulation of IL- 12 by iC 3 b deposited in ultraviolet-exposed human skin. J. Immunol. 161:5873-5879.

7. Hammerberg, C., Katiyar, S.K., Carroll, M.C., and Cooper, K.D. 1998. Activated complement component $3(\mathrm{C} 3)$ is required for ultraviolet induction of immunosuppression and antigenic tolerance. J. Exp. Med. 187:1133-1138.

8. Ohkohchi, K., Takematsu, H., and Tagami, H. 1986. Determination of anaphylatoxin concentrations in suction blisters in patients with psoriasis. J. Invest. Dermatol. 87:65-67.

9. Hugli, T.E. 1990. Structure and function of C3a anaphylatoxin. Curr. Top. Microbiol. Immunol. 153:181-208

10. Hollmann, T.J., Haviland, D.L., Kildsgaard, J., Watts, K., and Wetsel, R.A. 1998. Cloning, expression, sequence determination, and chromosome localization of the mouse complement C3a anaphylatoxin receptor gene. Mol. Immunol. 35:137-148.

11. Legler, D.F., et al. 1996. Expression of high- and low-affinity receptors for $\mathrm{C} 3 \mathrm{a}$ on the human mast cell line, HMC-1. Eur. J. Immunol. 26:753-758.

12. Daffern, P.J., Pfeifer, P.H., Ember, J.A., and Hugli, T.E. 1995. C3a is a chemotaxin for human eosinophils but not for neutrophils. I. C3a stimulation of neutrophils is secondary to eosinophil activation. J. Exp. Med. 181:2119-2127.

13. Stimler, N.P., Bloor, C.M., and Hugli, T.E. 1983. $\mathrm{C} 3 \mathrm{a}$-induced contraction of guinea pig lung parenchyma: role of cyclooxygenase metabolites. Immunopharmacology. 5:251-257.

14. Kirchhoff, K., et al. 2001. Detection of anaphylatoxin receptors on $\mathrm{CD} 83+$ dendritic cells derived from human skin. Immunology. 103:210-217.

15. Werfel, T., et al. 2000. Activated human T lymphocytes express a functional C3a receptor. J. Immunol. 165:6599-6605.

16. Fischer, W.H., Jagels, M.A., and Hugli, T.E. 1999. Regulation of IL- 6 synthesis in human peripheral blood mononuclear cells by C3a and C3a(desArg). J. Immunol. 162:453-459.

17. Fischer, W.H., and Hugli, T.E. 1997. Regulation of B cell functions by $\mathrm{C} 3 \mathrm{a}$ and $\mathrm{C} 3 \mathrm{a}($ desArg): suppression of TNF-alpha, IL-6, and the polyclonal immune response. J. Immunol. 159:4279-4286.

18. Kildsgaard, J., et al. 2000. Cutting edge: targeted disruption of the C3a receptor gene demonstrates a novel protective anti-inflammatory role for C3a in endotoxin-shock. J. Immunol. 165:5406-5409.

19. Humbles, A.A., et al. 2000. A role for the C3a anaphylatoxin receptor in the effector phase of asthma. Nature. 406:998-1001.

20. Bautsch, W., et al. 2000. Cutting edge: guinea pigs with a natural C3a-receptor defect exhibit decreased bronchoconstriction in allergic airway disease: evidence for an involvement of the C3a anaphylatoxin in the pathogenesis of asthma. J. Immunol. 165:5401-5405.

21. Liew, F.Y. 2002. T(H)1 and T(H)2 cells: a historical perspective. Nat. Rev. Immunol. 2:55-60.

22. O'Garra, A. 1998. Cytokines induce the development of functionally heterogeneous $\mathrm{T}$ helper cell subsets. Immunity. 8:275-283.

23. Hosken, N.A., Shibuya, K., Heath, A.W., Murphy, K.M., and O'Garra, A. 1995. The effect of antigen dose on CD4+ T helper cell phenotype development in a $\mathrm{T}$ cell receptor-alpha beta-transgenic model. J. Exp. Med. 182:1579-1584.

24. Constant, S., Pfeiffer, C., Woodard, A., Pasqualini, T., and Bottomly, K. 1995. Extent of T cell receptor ligation can determine the functional differentiation of naive CD4+ T cells. J. Exp. Med. 182:1591-1596.

25. Kuchroo, V.K., et al. 1995. B7-1 and B7-2 
costimulatory molecules activate differentially the Th1/Th2 developmental pathways: application to autoimmune disease therapy. Cell. 80:707-718.

26. Kalinski, P., Hilkens, C.M., Wierenga, E.A., and Kapsenberg, M.L. 1999. T-cell priming by type-1 and type- 2 polarized dendritic cells: the concept of a third signal. Immunol. Today. 20:561-567.

27. Macatonia, S.E., et al. 1995. Dendritic cells produce IL-12 and direct the development of Th 1 cells from naive CD4+ T cells. J. Immunol. 154:5071-5079.

28. Spergel, J.M., et al. 1998. Epicutaneous sensitization with protein antigen induces localized allergic dermatitis and hyperresponsiveness to methacholine after single exposure to aerosolized antigen in mice. J. Clin. Invest. 101:1614-1622.

29. Spergel, J.M., Mizoguchi, E., Oettgen, H., Bhan, A.K., and Geha, R.S. 1999. Roles of TH1 and TH2 cytokines in a murine model of allergic dermatitis. J. Clin. Invest. 103:1103-1111.

30. Ferluga, J., Schorlemmer, H.U., Baptista, L.C., and Allison, A.C. 1978. Production of the complement cleavage product, C3a, by activated macrophages and its tumorolytic effects. Clin. Exp. Immunol. 31:512-517.

31. Zwirner, J., Werfel, T., Wilken, H.C., Theile, E., and Gotze, O. 1998. Anaphylatoxin C3a but not $\mathrm{C} 3 \mathrm{a}$ (desArg) is a chemotaxin for the mouse macrophage cell line J774. Eur. J. Immunol. 28:1570-1577.

32. Trinchieri, G. 2003. Interleukin-12 and the regulation of innate resistance and adaptive immunity. Nat. Rev. Immunol. 3:133-146.

33. Snapper, C.M., and Paul, W.E. 1987. Interferongamma and B cell stimulatory factor- 1 reciprocally regulate Ig isotype production. Science. 236:944-947.

34. van Vlasselaer, P., Gascan, H., de Waal Malefyt, R., and de Vries, J.E. 1992. IL-2 and a contact-mediated signal provided by TCR alpha beta + or TCR gamma delta $+\mathrm{CD} 4+\mathrm{T}$ cells induce polyclonal Ig production by committed human B cells. Enhancement by IL-5, specific inhibition of IgA synthesis by IL-4. J. Immunol. 148:1674-1684.

35. Nies, J.H., et al. 2002. IL-4 supplemented B-cell cultures of allergic children show reduced IgA and IgG production in response to additional stimulation with IL-10. J. Investig. Allergol. Clin. Immunol. 12:99-106.

36. von Bulow, G.U., van Deursen, J.M., and Bram, R.J. 2001. Regulation of the T-independent humoral response by TACI. Immunity. 14:573-582.

37. Castigli, E., et al. 2004. Impaired IgA class switching in APRIL-deficient mice. Proc. Natl. Acad. Sci. U. S. A. 101:3903-3908.

38. Basset-Seguin, N., Caughman, S.W., and Yancey, K.B. 1990. A-431 cells and human keratinocytes synthesize and secrete the third component of complement. J. Invest. Dermatol. 95:621-625.

39. Terui, T., et al. 1997. C3 production of cultured human epidermal keratinocytes is enhanced by IFNgamma and TNFalpha through different pathways. J. Invest. Dermatol. 108:62-67.

40. Pasch, M.C., Van Den Bosch, N.H., Daha, M.R., Bos, J.D., and Asghar, S.S. 2000. Synthesis of complement components $\mathrm{C} 3$ and factor B in human keratinocytes is differentially regulated by cytokines. J. Invest. Dermatol. 114:78-82.

41. Ma, W., et al. 2002. CCR3 is essential for skin eosinophilia and airway hyperresponsiveness in a murine model of allergic skin inflammation. J. Clin. Invest. 109:621-628. doi:10.1172/JCI200214097.

42. Barbano, G., et al. 1999. Peritoneal mesothelial cells produce complement factors and express CD59 that inhibits C5b-9-mediated cell lysis. Adv. Perit. Dial. 15:253-257.

43. Kreuzpaintner, G., Damerau, B., Zimmermann, B., Plummer, T.H., Jr., and Brade, V. 1986. Inactivation of C3a by a monocarboxypeptidase present in culture supernatants of stimulated guinea pig peritoneal macrophages. J. Immunol. 136:3384-3389.

44. Drouin, S.M., Corry, D.B., Hollman, T.J., Kildsgaard, J., and Wetsel, R.A. 2002. Absence of the complement anaphylatoxin C3a receptor suppresses Th2 effector functions in a murine model of pulmonary allergy. J. Immunol. 169:5926-5933.

45. Gutzmer, R., et al. 2004. Human monocyte-derived dendritic cells are chemoattracted to C3a after upregulation of the $\mathrm{C} 3 \mathrm{a}$ receptor with interferons. Immunology. 111:435-443.

46. Saeki, H., Moore, A.M., Brown, M.J., and Hwang, S.T. 1999. Cutting edge: secondary lymphoid-tissue chemokine (SLC) and CC chemokine receptor 7 (CCR7) participate in the emigration pathway of mature dendritic cells from the skin to regional lymph nodes. J. Immunol. 162:2472-2475.

47. Sugiyama, S., et al. 1978. Prostaglandins released into human burn blister fluid. Biomedicine. 29:51-53.

48. Sato, Y., Ohshima, T., and Kondo, T. 1999. Regulatory role of endogenous interleukin-10 in cutaneous inflammatory response of murine wound healing. Biochem. Biophys. Res. Commun. 265:194-199. 